\title{
Correction to: Trajectory Analysis of the Rockfall Based on the Effect of Rotating Angular Velocity
}

\author{
Shaozhen Duan (1) - Wei Jin · Jinlong Sun - Wenda Wang
}

Published online: 13 December 2021

(C) Springer Nature Switzerland AG 2021

\section{Correction to:}

Geotechnical and Geological Engineering https://doi.org/10.1007/s10706-021-01863-3

The original publication of the article was incorrectly processed in large layout instead of medium layout.
Publisher's Note Springer Nature remains neutral with regard to jurisdictional claims in published maps and institutional affiliations.

The original article can be found online at https:// doi.org/10.1007/s10706-021-01863-3.

S. Duan $(\bowtie) \cdot$ W. Jin $\cdot$ J. Sun $\cdot$ W. Wang School of civil Engineering, Lanzhou University of Technology, Lanzhou 730050, Gansu, China e-mail: dszbest@126.com

W. Jin

e-mail: 923219942@qq.com

J. Sun

e-mail: 718707607@qq.com

W. Wang

e-mail: wangwd@lut.edu.cn 